\title{
BMJ Global Health The need for standard definitions in global data comparison: lessons from studying the prevalence of anaemia during pregnancy in Sri Lanka
}

\author{
Gayani Amarasinghe (D , ${ }^{1}$ Thilini Agampodi, ${ }^{1}$ Vasana Mendis, ${ }^{2}$ \\ Suneth Buddhika Agampodi (i) ${ }^{1}$
}

To cite: Amarasinghe $\mathrm{G}$, Agampodi T, Mendis V, et al. The need for standard definitions in global data comparison: lessons from studying the prevalence of anaemia during pregnancy in Sri Lanka. BMJ Global Health 2021;6:e005737. doi:10.1136/ bmjgh-2021-005737

Handling editor Seye Abimbola

Received 17 March 2021

Revised 21 April 2021

Accepted 24 April 2021
Check for updates

(C) Author(s) (or their employer(s)) 2021. Re-use permitted under CC BY-NC. No commercial re-use. See rights and permissions. Published by BMJ

${ }^{1}$ Department of Community Medicine, Faculty of Medicine and Allied Sciences, Rajarata University of Sri Lanka, Saliyapura, Sri Lanka

${ }^{2}$ Department of Pathology, Faculty of Medicine and Allied Sciences, Rajarata University of Sri Lanka, Saliyapura, Sri Lanka

Correspondence to

Prof Suneth Buddhika

Agampodi;

sunethagampodi@yahoo.com
Despite continuous efforts to combat anaemia in pregnancy, many countries are still far from controlling this global health issue. Daru et al have reported that even in the past decade, the odds of death among pregnant women with severe anaemia were 2.36 compared with other pregnant women. ${ }^{1}$ Though alarming, even these odds have been pointed out to be an underestimation of the actual magnitude of the problem calling for comprehensive strategies to address anaemia in pregnancy. ${ }^{2}$ Exerting universal consensus on definitions for anaemia in pregnancy is of utmost importance as such strategies require correct quantification of the disease burden and its distribution.

With its focus on universal healthcare, Sri Lanka has been able to achieve good maternal care indicators both in care coverage as well as outcomes. However, the Global Health Observatory Data Repository has placed Sri Lanka as a country with poor performance with regard to maternal anaemia, with more than 100 countries performing better than Sri Lanka. In 2018, prevalence of anaemia among Sri Lankan pregnant women was reported as $29.1 \%$, and 8 of its 25 districts reported that more than one-third of their pregnant population was anaemic. ${ }^{3}$

These prevalence data are compiled based on the National Guidelines for Maternal Care which recommends haemoglobin assessment at the booking visit and around 28 weeks of period of gestation (POG). In accordance with the previous $\mathrm{WHO}$ recommendations, the national pregnancy care programme uses a universal haemoglobin cut-off of $110 \mathrm{~g} / \mathrm{L}$ to identify anaemia throughout the pregnancy period. ${ }^{4}$ However, the revised WHO guideline recommends using a lower haemoglobin cut-off of $105 \mathrm{~g} / \mathrm{L}$ during the second trimester
Summary box

Accommodating for the changes in plasma volume during pregnancy, new recommendations suggest that the haemoglobin threshold for defining anaemia during pregnancy should be adjusted for the period of gestation.

- Still, same threshold value is being used throughout the pregnancy in some countries leading to a great overestimation of anaemia prevalence in pregnant women in those regions

- For an example, we observed that in Sri Lanka, two out of five women categorised as having anaemia in mid-pregnancy are not actually anaemic.

- At individual level, this may lead to unnecessary investigations, interventions and psychological disturbances in a large number of pregnant women.

- Heterogeneity in haemoglobin cut-off values used by countries to define anaemia may compromise the accuracy of global level disease burden comparisons, impacting the policy decisions based on them.

- National healthcare managers need to be vigilant on the global changes and the global data repositories and comparisons need additional steps in data curation in order to provide better estimates.

of pregnancy. ${ }^{5}$ Similar recommendations are being practised elsewhere in the world including the USA, UK and Australia. ${ }^{7-9}$

A recent large community-based pregnancy cohort study conducted in Sri Lanka (Rajarata Pregnancy Cohort) provided comprehensive data on the probable overestimation of anaemia in pregnancy due to the differences in the threshold values used. ${ }^{10}$ The study was conducted in Anuradhapura, a district where the reported prevalence of anaemia in pregnancy was almost 50\%. According to the maternal health statistics of the district, the cohort had included $86 \%$ of its pregnant population registering for antenatal care from July to September 2019. ${ }^{11}$ Among 1366 
pregnant women with POG between 22 and 32 weeks, only $373(27.3 \%)$ were identified as anaemic using the globally accepted threshold of $105 \mathrm{~g} / \mathrm{L}$. However, according to the information relayed to national pregnancy care programme, $676(49.5 \%)$ pregnant women were anaemic, based on the current national recommendation (haemoglobin $110 \mathrm{~g} / \mathrm{L}$ as threshold). This is a gross $78.7 \%$ inflation of prevalence estimate where anaemia prevalence has increased by 22.2 percentage points.

At individual level, this may lead to unnecessary investigations and psychological disturbances in a large number of pregnant women. At national level, the overestimation can cloud the success of effective preventive strategies, undermine the efforts and dedication of grass-root level healthcare providers leading to frustration and demotivation, and can unnecessarily exhaust the already limited human and physical resources. The accuracy of global rankings and classifications, and hence their usefulness as data for action at global level, is also at stake when countries have used different cut-offs to estimate anaemia prevalence. Thus, national healthcare managers need to be vigilant on global changes and the global data repositories and comparisons need additional steps in data curation in order to provide better estimates.

Contributors GA was involved in the conceptualisation, designing, conducting the research, data cleaning, and analysis and preparation of the draft. TA was involved in the conceptualisation, designing, supervision of the research, and critically reviewing the draft. VM was involved in the designing, conducting the research and critically reviewing the draft. SBA was involved in the conceptualisation, designing, supervising the research, data cleaning and analysis, preparation of the draft and critically reviewing the draft.

Funding This work was supported by the Accelerating Higher Education Expansion and Development (AHEAD) Operation of the Ministry of Higher Education, Sri Lanka, funded by the World Bank.

Disclaimer The funding body had no involvement in the methodology development, collection and analysis of data or writing the manuscript.

Competing interests None declared.

Patient consent for publication Not required.
Provenance and peer review Not commissioned; externally peer reviewed.

Data availability statement Data are available upon request.

Open access This is an open access article distributed in accordance with the Creative Commons Attribution Non Commercial (CC BY-NC 4.0) license, which permits others to distribute, remix, adapt, build upon this work non-commercially, and license their derivative works on different terms, provided the original work is properly cited, appropriate credit is given, any changes made indicated, and the use is non-commercial. See: http://creativecommons.org/licenses/by-nc/4.0/.

\section{ORCID iDs}

Gayani Amarasinghe http://orcid.org/0000-0002-7473-0853

Suneth Buddhika Agampodi http://orcid.org/0000-0001-7810-1774

\section{REFERENCES}

1 Daru J, Zamora J, Fernández-Félix BM, et al. Risk of maternal mortality in women with severe anaemia during pregnancy and post partum: a multilevel analysis. Lancet Glob Health 2018;6:e548-54.

2 Young MF. Maternal anaemia and risk of mortality: a call for action. Lancet Glob Health 2018;6:e479-80.

3 Family Health Bureau Sri Lanka. Annual report of the family health bureau 2018. Colombo 102020.

4 Ministry of Health. National Guidlines for maternal care III:3-96, 2015. Available: www.familyhealth.gov.lk

5 WHO e-Library of Evidence for Nutrition Actions (eLENA). Daily iron and folic acid supplementation during pregnancy, 2019. Available: https://www.who.int/elena/titles/daily_iron_pregnancy/en/

6 World Health Organization. Who recommendations on antenatal care for a positive pregnancy experience, 2016. Available: https:// apps.who.int/iris/bitstream/handle/10665/250796/9789241549912eng.pdf;jsessionid=9153B887931D998774FF9E102CF601DA? sequence $=1$

7 Pavord S, Myers B, Robinson S, et al. UK guidelines on the management of iron deficiency in pregnancy. $\mathrm{Br} \mathrm{J}$ Haematol 2012;156:588-600

8 Centre for Disease Control CDC U.. Recommendations to prevent and control iron deficiency in the United States. Available: https:// www.cdc.gov/mmwr/preview/mmwrhtml/00051880.htm\#00003038. htm [Accessed 26 Nov 2020].

9 Australian Government Department of Health. Anaemia. pregnancy care Guidel, 2019. Available: https://www.health.gov.au/resources/ pregnancy-care-guidelines/part-f-routine-maternal-health-tests/ anaemia [Accessed 1 Dec 2020].

10 Agampodi TC, Wickramasinghe ND, Prasanna RIR, et al. The Rajarata pregnancy cohort (RaPCo): study protocol. BMC Pregnancy Childbirth 2020;20:1-13.

11 Amarasinghe G, Mendis V, Agampodi T. Cross-Sectional study to assess etiology and associated factors for anaemia during first trimester of pregnancy in Anuradhapura district, Sri Lanka: a protocol. F1000Res 2021;10:223. 